\title{
Aspectos económicos del primer año de gestión gubernamental
}

El primer año de gobierno de Francisco Flores transcurrió en medio de las expectativas que generaron sus ofrecimientos de campaña y de discurso, pues, al igual que su precedente, el gobierno actual inició su gestión sin haber especificado los objetivos que buscará alcanzar a través de la política económica. El documento "Alianza para el progreso" —que constituyó la plataforma electoral de Flores- despertó demasiadas expectativas, aunque sólo presenta los objetivos generales de cada área programática, sin precisar los objetivos e instrumentos específicos que aplicará para lograrlos.

Por lo menos, el primer gobierno de ARENA sí elaboró un plan de desarrollo económico y social lo suficientemente detallado como para conocer el modelo económico que se perseguía. De hecho, a partir de ese plan se iniciaron las políticas de corte neoliberal, que incluyeron la liberalización de precios y las actividades económicas, las privatizaciones, la "modernización" del Estado y, en general, la redefinición de la función del Estado en la economía y la sociedad. Se abrió así un ciclo de reformas que - aunque a algunos les disguste-condujeron a la no muy favorable situación económica actual, la cual debe ser enfrentada por el gobiemo de Flores.

A juzgar por las medidas adoptadas al final de su primer año de gestión (políticas sectoriales e incremento de aranceles), parece que el presidente Flores no está totalmente convencido de las bon- dades de las reformas económicas desarrolladas por sus dos predecesores aunque, pese a ello, no ha planteado cambios de consideración en el modelo económico. El componente económico de la nueva alianza - la plataforma electoral de gobierno- y del discurso de toma de posesión del presidente Flores, se constituyeron en los lineamientos de la política económica que -independientemente de su pertinencia - son importantes referentes a la hora de evaluar el primer año de gobiemo; asimismo, las estrategias que deberían adoptarse para superar el actual escenario de crisis, caracterizado por la presencia de varios factores desestabilizantes y restrictivos (déficit externo y fiscal, restricciones monetarias, elevadas tasas de interés). A continuación se evalúa el primer año de gestión económica a partir de una revisión de los ofrecimientos de campaña y toma de posesión, de las medidas implementadas y los problemas económicos objetivos y sus posibles líneas de solución.

\section{Los ofrecimientos}

En materia económica, la plataforma electoral del actual gobierno establecía la adopción de una "alianza por el trabajo" con cuatro grandes áreas: políticas sectoriales, políticas de apoyo a la productividad, nuevas políticas laborales y políticas para mejorar los espacios y vínculos de los salvadoreños en el exterior' ${ }^{\prime}$. Al revisar los componentes de cada una de estas áreas se detecta rápida-

1. Ver ARENA, La nueva alianza, 1999, s.e., San Salvador. Para un resumen, consulte Centro de Información, Documentación y Apoyo a la Investigación (CIDAI), "Las plataformas de gobierno de ARENA y FMLN-USC", en Estudios Centroamericanos, (ECA), 604-605, febrero-marzo, 1999, pp. 217-232. 
mente que persiguen objetivos demasiado generales. Por lo mismo, no definen cuáles serán las medidas concretas sobre política económica que serán impulsadas.

Los ofrecimientos de la "alianza por el trabajo" hacen honor a su categoría de "plataforma política", porque parecen demasiado buenos para ser realidad y dejan de lado temas altamente sensibles como el déficit de las finanzas públicas, la profundización del déficit comercial y la restrictividad de la política monetaria.

En su discurso de toma de posesión, el presidente Flores elevó la "nueva alianza" - y, por tanto, elevó la "alianza para el trabajo" a la categoría de programa de gobierno-, aunque agregó otras políticas para mantener la estabilidad y la "predictibilidad" económica: "fijar en el ancla segura de nuestras leyes" el tipo de cambio, el saneamiento de las finanzas públicas y el fortalecimiento de la micro, pequeña y mediana empresa ${ }^{2}$. También reiteró su compromiso con el sector agropecuario, al cual ofreció, en esta ocasión, la construcción de infraestructura; promover la asociatividad de agricultores, fomentar el microcrédito rural y promover un flujo de información oportuna sobre "precios, tecnologías, productos y mercados"3.

\section{Las medidas efectivas}

Estas pueden clasificarse en tres diferentes grupos: los vetos a varios decretos legislativos con implicaciones sobre el gasto público, los esfuerzos por incrementar la recaudación del IVA (a través de la eliminación de exenciones y la reducción de la evasión) y, finalmente, el programa agrario.

Los vetos a proyectos de ley tuvieron matices políticos y económicos porque surgieron en el contexto de una prolongada huelga en el sector salud y de un sustancial incremento en el déficit fiscal, que podía justificar cualquier decisión de vetar decretos que supusieran incrementar el gasto público. Así, a partir de noviembre, Flores vetó cuatro decretos legislativos relacionados con incrementos salariales, pago a trabajadores huelguistas y creación de un fondo de compensación eco- nómica para ex combatientes del conflicto armado. Estas decisiones provocaron que empleados del Órgano Judicial y del Instituto Salvadoreño del Seguro Social no recibieran aumentos salariales, que se retuviera el pago de los días no laborados a un grupo de maestros huelguistas y que se negaran las demandas de compensación económica exigidas por los desmovilizados de la defensa civil. En todos los casos, los decretos implicaban mayores erogaciones y esa fue la justificación que dio Flores para su veto.

Siempre vinculado al tema de las finanzas públicas, el gobierno ha realizado esfuerzos para reducir la evasión fiscal mediante la promoción de reformas a la ley del IVA, de tal manera que no sea posible utilizar de forma indiscriminada el crédito fiscal y, con ello, la evasión del pago del citado impuesto sobre el consumo de los contribuyentes inscritos. Adicionalmente, se propusieron y obtuvieron otras reformas a la ley del IVA, en el sentido de eliminar las exenciones a los productos agropecuarios y farmacéuticos lo cual, aunque ha sido planteada más como una medida para la reactivación del agro, tiene fuertes implicaciones tributarias e inflacionarias.

La medida de mayor trascendencia adoptada durante el primer año del gobierno de Flores ha sido el programa de reactivación del sector agropecuario. Este plan, que combina medidas crediticias, fiscales y de inversión pública, pretende enfrentar el ya casi sempiterno problema de la contracción de la producción y del empleo agropecuario. Sus principales líneas de acción se resumen en lo siguiente: eliminación de las exenciones al Impuesto al Valor Agregado (IVA) para productos agropecuarios, un plan crediticio para fomentar el cultivo de café y el aumento de los aranceles para algunos productos agropecuarios ${ }^{4}$.

De entrada puede señalarse que la estrategia agropecuaria es problemática por no incluir a los agricultores de subsistencia entre los beneficiarios. Primero porque las exenciones al IVA sólo favorecen a los contribuyentes inscritos; segundo porque la producción para la venta generada por estos

2. Ver "Primer discurso presidencial. Lic. Francisco Flores. Discurso de toma de posesión", en Estudios Centroamericanos, (ECA), 607-608, mayo-junio, 1999, pp. 561-565.

3. Ídem.

4. Más detalles pueden consultarse en CIDAI, "La política agropecuaria del gobicrno", en El Salvador Proceso, 901, 2000, pp. 6-7. 
agricultores es ínfima, lo cual prácticamente los excluye de los probables beneficios de un incremento de precios resultante de la incorporación del IVA y del incremento de los aranceles; y, tercero, porque los agricultores de subsistencia no son precisamente sujetos de crédito ni mucho menos poseen cafetales o tierras aptas para plantarlos.

Además, los ofrecimientos para proporcionar mayor asistencia técnica y crediticia al sector campesino no han sido las medidas más enfatizadas, aunque fueron parte de los ofrecimientos del discurso de toma de posesión, don-

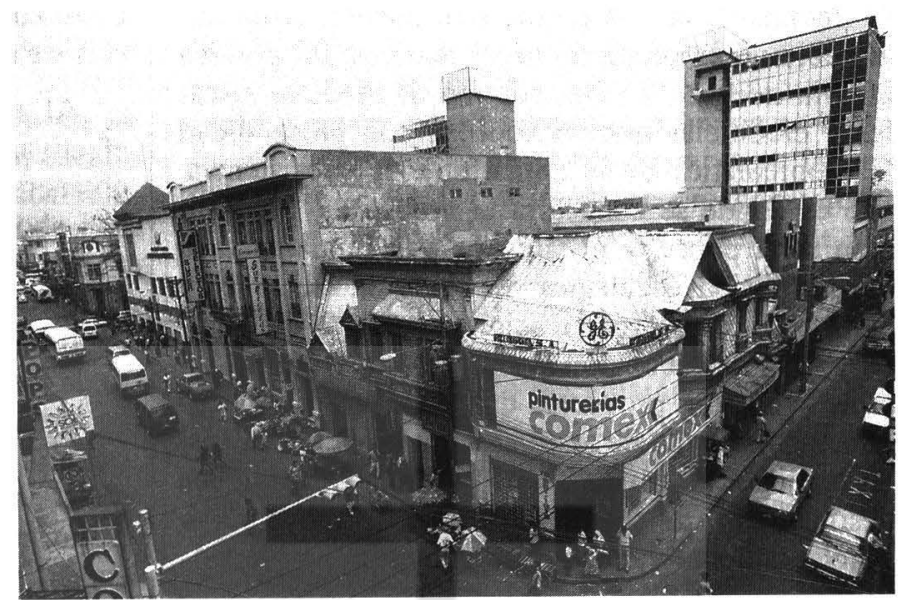
de Flores mencionó que promovería el "desarrollo del microcrédito rural" y la "información oportuna sobre precios, tecnologías, productos y mercados". Sin embargo, no puede obviarse que este es un ofrecimiento que requiere implementar planes profundos de reestructuración de la investigación y del extensionismo agropecuario que, además, pasa por la dotación de mayores y mejores recursos a las dependencias vinculadas al $\mathrm{Mi}$ nisterio de Agricultura y Ganadería y especialmente al Centro Nacional de Tecnología Agropecuaria, los cuales han venido de mal en peor en los gobiernos de ARENA.

Otros aspectos que el gobierno menciona como logros de su gestión han sido los tratados de libre comercio y la ampliación de los beneficios de la Iniciativa de la Cuenca del Caribe. Sin embargo, esto no es un logro exclusivo del gobiemo, pues ha sido un proceso que lleva más de ocho años y en el cual también han participado otros gobiernos. El hecho de que El Salvador haya participado en estos acuerdos no se debe a una visión estratégica o a la iniciativa del gobiemo actual, sino que más bien es la cosecha de los frutos de un largo proceso de negociaciones.

La evaluación del Presidente sobre su gestión económica en el primer año de gobierno, como era de esperar, es más optimista de lo debido, en especial si consideramos las medidas ejecutadas. En el discurso de su primer aniversario, el presidente Flores sostuvo frente a la Asamblea Legislativa que, en resumen, sus logros en materia económica serían:

la Iniciativa de la Cuenca del Caribe, el tratado de libre comercio con México, el acuerdo del triángulo del Pacífico con Guatemala y Nicaragua, la reactivación del puerto de Cutuco y la instalación del ferry, una política agropecuaria integral, un sistema de apoyo para la pequeña empresa, una red vial sostenible, un esfuerzo coherente de atracción de inversiones; un mayor dinamismo de la economía sustentado en un repunte de las exportaciones, una moneda estable, un déficit decreciente, tasas de interés en reducción y un mayor ritmo de crecimiento 5 .

Esta evaluación contiene una fuerte dosis de demagogia, que se evidencia en por los menos dos puntos: primero, porque incluye en los logros la suscripción de tratados que -además de que en sí mismos no son beneficios- han venido siendo negociados por dos o tres gobiernos y, además, no habrian sido posibles sin la aceptación de los demás gobiemos partes; segundo, porque atribuye a la política económica resultados que, en realidad, son posibles sólo gracias a la afluencia de las remesas familiares (como la "moneda estable") o a las políticas de la banca privada (reducción de las tasas de interés); y tercero, porque convierte en logros aspectos que son más bien debilidades: el mayor dinamismo de la economía no es tal si se analizan los indicadores de la coyuntura, y el "déficit (fiscal) decreciente", en realidad, aún está en niveles superiores al de 1998.

5. Francisco Flores, "Informe del primer año de gobierno ante la Asamblea Legislativa, por el señor Presidente de la República", El Diario de Hoy, 2 de junio de 2000, pp. 72 y 73. 
Inclusive, en los logros que pueden atribuirse al gobierno es necesario hacer matices: la "política agraria integral" es un conjunto de medidas fiscales y crediticias que no abordan con profundidad la problemática de la agricultura de subsistencia, que es donde se concentra el grueso de la población rural pobre, y ni siquiera está fundamentada en una visión estratégica de polos de crecimiento agropecuario; la "reactivación del puerto de Cutuco y la reactivación del ferry" y la "red vial sostenible" son sólo proyectos que pueden o no ejecutarse; el "sistema de apoyo a la microempresa" es, en realidad, un fondo de 168 millones de colones destinado a fortalecer instituciones de apoyo, cuyo funcionamiento y efectividad aún están por verse.

El optimismo presidencial posiblemente podría tener cabida si se considerara que si el senado estadounidense hubiera decidido no prolongar más los beneficios de la Iniciativa de la Cuenca del Caribe, en El Salvador se hubieran experimentado efectos negativos sobre ciertas exportaciones dirigidas hacia Estados Unidos, pero el efecto hubiera sido especialmente grave sobre la actividad de maquila de ropa y el empleo que ésta genera que -dicho sea de paso- es de los más dinámicos del conjunto de la economía. Otra posible razón para ser optimista es que el Tratado de Libre Comercio con México se dio en un momento en que ese país presionaba para no continuar con el denominado Acuerdo de Alcance Parcial, a través del cual muchos productos salvadoreños gozaban de preferencias arancelarias $y$, por tanto, puede aparecer como un gran logro, pues se tiene un Tratado de Libre Comercio que elimina la dependencia del Acuerdo de Alcance Parcial y, por consiguiente, la incertidumbre que generaba su posible cancelación.

El Tratado de Libre Comercio y la Iniciativa de la Cuencia del Caribe no son logros, sino más bien oportunidades, pues el que arrojen resultados positivos dependerá mucho de la capacidad de las estructuras productivas nacionales para aprovechar las oportunidades abiertas. En muchos casos, los tratados de libre comercio han hecho que los países con menor desarrollo relativo experimenten la profundización de su déficit comercial y la desaparición de empresas o hasta las actividades productivas. Basta mencionar el caso del Tratado de Libre Comercio Canadá Estados Unidos, donde la primera se está llevando la peor parte o, sin ir más lejos, el mercado común centroamericano, el cual trajo para Honduras y Nicaragua más daño que beneficio.
Problemas, carencias y posibles líneas prioritarias de acción

Al analizar los ofrecimientos y las medidas efectivas del gobiemo de Francisco Flores, pueden obtenerse las siguientes conclusiones: (1) No se han abordado con la profundidad debida, algunos ni siquiera han sido abordados, temas trascendentales como las medidas de apoyo a la productivi$\mathrm{dad}$, las "nuevas relaciones laborales" y el fomento de la micro, pequeña y mediana empresa. (2) Se ha avanzado en la implementación de políticas sectoriales - pues se han adelantado medidas dirigidas hacia el agro-, aunque simultáneamente se ha postergado la política de reactivación del sector construcción. Con todo, la política anunciada para el agro adolece todavía de evidentes incoherencias internas, resultado de la ausencia de una visión estratégica de largo plazo. (3) Tampoco se ha fijado el tipo de cambio, tal y como el presidente lo anunció en su discurso de toma de posesión, tampoco se ha avanzado mucho en el saneamiento de las finanzas públicas, debido a que, aunque se implementan medidas para incrementar los ingresos, no se hace lo mismo para controlar el crecimiento del gasto público.

En materia económica, algunas carencias del "programa de gobiemo" pueden surgir del análisis de los indicadores de coyuntura, los cuales reflejan: (1) Permanencia de un ciclo de lento crecimiento económico e insuficiente generación de empleo productivo. El crecimiento del 2.2 por ciento alcanzado en 1999 está por debajo del promedio del período 1992-1999 (2.7 por ciento); además, cerca del 39 por ciento de la población se encuentra en situaciones precarias debido al desempleo y subempleo. (2) Estancamiento de los salarios. Los salarios mínimos reales se estancaron en los niveles de 1990 y los salarios promedio reales apenas se incrementaron 0.7 por ciento en 1999. (3) Profundización del déficit de la balanza comercial y de la dependencia de las remesas familiares. Existe un elevado déficit en la balanza comercial, que alcanzó un impresionante 13.2 por ciento del producto interno bruto que, afortunadamente, sólo genera un déficit de cuenta corriente equivalente a un 1.6 por ciento del PIB, debido a la "amortización" que permiten las remesas familiares. (4) Incremento del déficit fiscal. En 1999 se alcanzó el nivel de déficit más alto registrado desde 1990 (3 por ciento del PIB) y para el 2000 se proyecta que disminuya sólo de forma leve hasta 
alcanzar un 2.6 por ciento del producto interno bruto. (5) Excesiva restrictividad de la política monetaria. Esta se refleja en la reducción en las tasas de crecimiento de la masa monetaria, encajes legales elevados y fuerte emisión de títulos valores, que favorecen la permanencia de elevadas tasas de interés real. (6) Creciente concentración de la banca y el sistema financiero e incremento en las tasas de interés reales. Además de las influencias de la política monetaria, en la banca existen prácticas poco competitivas y de canibalismo, que están conduciendo a una situación de oligopolio y de fijación de tasas de interés real demasiado elevadas $^{6}$.

A partir de lo anterior puede decirse que algunas medidas requieren una rápida y decidida implementación: (1) La definición de polos de desarrollo, que serán los principales motores del crecimiento de la producción y las exportaciones. (2) Fomentar la integración de los sectores campesinos y de la microempresa a la actividad de los polos de desarrollo. (3) Incluir dentro de las políticas de las "nuevas relaciones laborales" la revisión periódica de los salarios mínimos y el fomento de actividades que distribuyan de forma equitativa el valor agregado. (4) Reconsiderar la política de fomento de las exportaciones tradicionales para incluir rubros no tradicionales. (5) Incorporar en las políticas de vínculos con los salvadoreños en el exterior, medidas que procuren el uso productivo de las remesas familiares (6) Mayor eficiencia en la asignación del gasto público y ejecución de nuevas reformas al sistema tributario. (7) Revisar la política monetaria eliminando restricciones al crecimiento del crédito y a la reducción de las tasas de interés. (8) Promover la rápida discusión, aprobación y aplicación de leyes de fomento de la libre competencia y antimonopolio.

El desempeño del gobierno en el campo económico ha tenido, lógicamente, resultados variables. En unos campos ha avanzado con lo prometi- do; en otros no, y en otros ni siquiera se cuenta con la visión estratégica que dará dirección a la política económica. La muestra palmaria es la política de financiamiento preferencial para la producción cafetalera, que se da en un momento en que están por cumplirse diez años de crisis de este sector, debido a la constante caída en los precios internacionales del café. Así, probablemente, se financiará el surgimiento o crecimiento de agroempresas que en el futuro necesitarán del apoyo gubernamental para seguir subsistiendo (tal como sucede en la actualidad). Adicionalmente, pretender centrar el desarrollo agropecuario en una actividad que tiene casi 150 años de venir demostrando no ser ninguna solución para la problemática de la pobreza rural es, sencillamente, inaceptable.

Aunque el presiderite implementara todas las medidas que ha anunciado, estas no arrojarán resultados óptimos mientras no se definan los sectores económicos cuya actividad será necesario promover con las políticas económicas. Así, la discusión ya no se centra en si el Estado debe intervenir o no en la economía para corregir sus problemas y eliminar los cuellos de botella, sino más bien en la forma y los medios que deben seguirse para hacer tal intervención.

Al parecer, los funcionarios gubernamentales son de la idea de que la intervención debe enfatizar la negociación de acuerdos comerciales, el fomento de actividades agropecuarias tradicionales $y$, por supuesto, el mantenimiento de la estabilidad macroeconómica (algo no muy difícil de lograr gracias a las remesas familiares); sin embargo, en el fondo, lo que se necesita es implementar políticas tendientes a crear y fomentar las capacidades productivas internas, las cuales son, a final de cuentas, las que determinarán que las oportunidades se traduzcan en avances o retrocesos.

\section{Luis Ernesto Romano Martínez}

6. Para mayor información, consulte Departamento de Economía de la UCA, "Análisis de coyuntura económica. Segundo semestre de 1999", en Estudios Centroamericnanos, (ECA), 615-616, cnero-febrcro, 2000, pp. 19-58. 